\title{
Contribuição de parâmetros do entorno urbano sobre o ambiente térmico de um campus universitário
}

\author{
Contribution of urban environment parameters on the \\ thermal environment of a University Campus
}

\section{Pedro Renan Debiazi \\ Léa Cristina Lucas de Souza}

\section{Resumo \\ $\mathbf{E}$}

ste artigo investiga a influência de algumas características do entorno urbano sobre a temperatura do ar, considerando parâmetros urbanos como o coeficiente de ocupação do solo $(\mathrm{CO})$, coeficiente de vegetação urbana (CVU), fator de visão de céu (FVC) e coeficiente de cobertura do solo (CCS). O espaço amostral utilizado é o campus da Universidade Federal de São Carlos, em São Carlos, SP, Brasil. O método emprega dataloggers para medições de temperatura do arem diferentes pontos de coleta, além da determinação de índices urbanísticos nesses pontos amostrais. Os dados térmicos e urbanísticos são relacionados entre si por desenvolvimento de modelos deredes neurais artificiais (RNA), considerando-se três raios de abrangência ao redor dos pontos amostrais: $25 \mathrm{~m}, 50 \mathrm{~m}$ e $100 \mathrm{~m}$. Dentre os modelos de previsão desenvolvidos, o de melhor desempenho é incorporado a um sistema de informação geográfica (SIG), permitindo a simulação de dados para outros pontos do campus e viabilizando a criação de mapas térmicos mais detalhados. Os resultados demonstram que o CVU é o elemento mais significativo na determinação do padrão térmico do campus e que os modelos de RNA associados à plataforma SIG podem ser instrumentos úteis para o apoio às ações que visem a qualidade térmica do campus.

Palavras-chave:Clima urbano.Fator de visão do céu. Vegetação urbana. Sistemas de informações geográficas. Redesneuraisartificiais.

\begin{abstract}
This paper investigates the influence of some characteristics of the urban environment on the air temperature by considering urban parameters such as occupancy coefficient (OC), urban vegetation coefficient (UVC), sky view factor (SVF) and cover coefficient (CC). The campus of the Federal University of São Carlos, in São Carlos, Brazil was used for spatial sampling. The method uses dataloggers for air temperature measurements in different collecting points, as well as the determination of urban indexes. The data of temperature and urban indexes are related to each other by the development of Artificial Neural Networks (ANN) models considering three radii around the sampling points: 25, 50 and 100 $m$. Among the prediction models developed, the one with the best performance is incorporated into a Geographical Information System (GIS), allowing data simulation of other points on the campus and leading to the creation of more detailed thermal maps. The results show that the UVC was the most significant element determining the thermal patterns in the campus. Furthermore, the ANN models associated with the GIS platform may be useful tools to support actions aiming at the thermal quality of the campus.
\end{abstract}

Pedro Renan Debiazi Estácio Carapicuíba Carapicuíba - SP - Brasil

Léa Cristina Lucas de Souza Universidade Federal de São Carlos São Carlos - SP - Brasil

Recebido em 14/01/16 Aceito em 09/01/17
Keywords: Urban climate. Sky view factor. Urban vegetation. Geographical Information Systems. Artificial neural networks. 


\section{Introdução}

A crescente demanda por cidades mais sustentáveis, energeticamente mais eficientes e termicamente mais confortáveis, tem pautado, sobretudo na última década, pesquisas na área da engenharia urbana e ambiental (JOHANSSON et al., 2014; WANG; AKBARI, 2014). Buscam-se criar instrumentos e desenvolver estratégias que contribuam para o melhor desempenho ambiental das cidades, de forma a colaborar para o aumento da qualidade de vida. Incluem-se, nesse contexto, estudos focados na análise do ambiente térmico urbano.

Segundo Carfan e Galvani (2012) e Gómez, Higueras e Escalona (2014), alguns efeitos prejudiciais à saúde humana podem ser causados pelos elevados índices de estresse térmico em áreas urbanizadas.

Quando as políticas de planejamento urbano e ordenamento do solo estão voltadas prioritariamente a atender o interesse econômico, podem levar ao desenvolvimento de cenários desfavoráveis ao conforto térmico dos usuários e ao ambiente microclimático (AMIRTHAM; HORRISON; RAJKUMAR, 2015).

Dessa maneira, com o intenso processo de urbanização e adensamento das cidades, aliados à grande variedade das formas de ocupação urbana, podem ocorrer graves problemas de ordem social e organizacional. Com isso, os usuários dos espaços abertos podem estar sujeitos a diferentes microclimas e situações de estresse térmico durante um mesmo dia, agravando o desconforto térmico (COHEN; POTCHTER; MATZARAKIS, 2013).

Dentre os fatores que influenciam a condição térmica nas cidades, podem ser citados alguns parâmetros do entorno urbano, tais como: o $\mathrm{CO}$, o CCS, FVC e o CVU. Estes indicam características do espaço físico, que atuam em conjunto com os fatores climáticos de cada região, tais como a latitude, a longitude, a altitude e o bioma (BOURBIA; BOUCHERIBA, 2010; SOUZA, 2010; MARROQUIM; CRUZ; BARBIRATO, 2014).

A forma de ocupação e a densidade construtiva alteram o ambiente microclimático, pois, segundo Oke (1973), podem influenciar na temperatura do ar no nível do solo, alterando também o regime e a velocidade dos ventos, afetando, consequentemente, o balanço energético.

Além disso, a geometria das construções e o arranjo paisagístico afetam diretamente a magnitude e o regime de entrada (ondas curtas) e saída (ondas longas) de energia disponível para as trocas térmicas entre as superfícies e o céu (ABREU-HARBICH; LABAKI; MATZARAKIS, 2015).

No balanço de energia urbano, o céu é um importante elemento para o equilíbrio térmico. Por ser naturalmente mais frio que o solo terrestre, o céu é essencial para as trocas de calor e para a dispersão de ondas longas emitidas pelas superfícies e fachadas durante a noite. Por isso, a faixa de céu disponível a partir de um observador na área urbana é uma informação relevante para a compreensão do ambiente térmico (OKE, 1973).

Uma forma de se analisar essa influência é por meio da aplicação do conceito de FVC. Este índice assume valores entre 0 (totalmente fechado) e 1 (totalmente descampado) e é determinado pela área de céu contida entre os limites obstruídos por qualquer elemento físico, natural (vegetação) ou artificial (edifícios, coberturas, etc.). O FVC indica a faixa de céu disponível para as trocas térmicas entre os elementos urbanos (SOUZA et al., 2010; MATZARAKIS; RUTZ; MAYER, 2010).

Locais com baixo valor de FVC podem apresentar menores temperaturas do ar durante o dia, em decorrência da menor incidência da radiação de onda curta. Entretanto, durante o período noturno, esses locais passam a enfrentar maior dificuldade na dispersão de ondas longas durante a troca de calor com o céu, afetando consequentemente o balanço energético. Assim, locais com baixo FVC contribuem para maior acúmulo térmico e menores taxas de arrefecimento (SOUZA et al., 2010).

Interfere ainda nessas trocas de calor a vegetação urbana, agindo como elemento de regulação das temperaturas nas cidades. Por seu comportamento natural, as áreas vegetadas podem atenuar os efeitos de aquecimento nas superfícies e fachadas, causadas pela incidência direta de radiação solar. A vegetação absorve parte dessa radiação, e possui diferente comportamento para diferentes comprimentos de onda de acordo com cada espécie. Entretanto, áreas muito arborizadas, com árvores de copas muito densas, podem, em determinadas épocas do ano, devido à variação sazonal, dificultar a dispersão de ondas longas no período noturno, por influenciar o FVC (ZHANG et al., 2014; LÓIS; LABAKI; SANTOS, 2011). Debiazi e Souza (2015), ao estudarem o papel da vegetação e o fator de visão de céu, também apontaram que locais muito arborizados, com árvores de copas densas e FVC baixo, criaram um bolsão térmico, que manteve as temperaturas sutilmente mais elevadas durante a noite. 
As coberturas das superfícies e fachadas também exercem influência na alteração da temperatura e umidade relativa do ar. Superfícies naturais, como áreas vegetadas e áreas permeáveis, possuem calor específico maior do que os materiais artificiais, e são em geral mais frias que as superfícies impermeabilizadas e artificiais, por isso garantem maior atraso no armazenamento e menor ganho de energia (ANDREOU, 2013; YAN et al., 2014).

Rocha e Souza (2011) reforçam que é devido à complexidade térmica encontrada na escala intraurbana que o conforto térmico em áreas abertas é resultado de um difícil equilíbrio entre o uso e ocupação do solo, a obstrução do céu e as demais variáveis climáticas locais, regionais e globais. Desenvolver ferramentas e modelos de avaliação sobre a contribuição relativa desses parâmetros é essencial para que os estudos sobre o microclima identifiquem modelos de ocupação, que permitam alcançar o equilíbrio entre os diversos fatores bioclimáticos e os elementos do entorno urbano.

Xiaodong et al. (2015) destacam que o planejamento territorial climaticamente orientado é um extraordinário desafio para os urbanistas e gestores, e que os estudos sobre o clima urbano impõem também grandes desafios tecnológicos para a criação e o uso de instrumentos de análise na tomada de decisões em longo prazo.

Sistemas de informações geográficas (SIG) são um desses instrumentos que têm sido abertamente empregados no desenvolvimento de ferramentas e métodos para planejamento territorial, com incorporação de modelos de previsão e criação de mapas temáticos. Esses mapas temáticos, por meio de métodos multicritérios, podem ter aplicação direta em planos de ação e estratégias de planejamento urbano (STEWART; JANSSEN, 2014).

Um SIG integra diversas tecnologias, reunidas em conjuntos de ferramentas que são capazes de armazenar e processar dados espaciais e quaisquer outros conjuntos de dados a eles vinculados ou atribuídos. A aplicação dessa ferramenta permite um maior controle e reconhecimento dos parâmetros locais e regionais, bem como maior controle sobre a aquisição, integração, transformação e emissão de dados (STEINIGER; HUNTE, 2013; SILVA et al., 2004).

Paralelamente aos SIG, a criação de modelos desenvolvidos pela técnica das RNA permite estabelecer relações complexas entre variáveis, que auxiliam na compreensão dos fenômenos ocorridos no espaço urbano. As RNA foram concebidas com base na fisiologia do cérebro humano e podem reproduzir, mediante técnicas computacionais, o comportamento de qualquer função matemática. São amplamente utilizadas para criar modelos de relações previamente conhecidas ou não entre as variáveis envolvidas (SILVA et al., 2004).

As RNA já foram anteriormente utilizadas com sucesso para prever dados climáticos, como o potencial de evapotranspiração, a temperatura do ar, a umidade relativa, as horas de sol do dia, dentre outras variáveis, como velocidade do vento e precipitações. Quando se trata de um grande conjunto de dados complexos, os modelos criados a partir de RNA podem, em alguns casos, apresentar melhores resultados do que os tradicionais modelos de regressão (PATEL; JHA, 2014; EL-SHAFIE et al., 2014).

Adota-se, portanto, neste artigo, uma abordagem que aplica ferramentas de um SIG associadas à técnica das RNA. Objetiva-se, com isso, investigar a contribuição relativa de alguns parâmetros urbanos sobre o ambiente microclimático, de forma a ser identificada a contribuição relativa entre os elementos do entorno urbano e o microclima. Para isso, estabeleceu-se um universo amostral pertencente a um campus universitário brasileiro.

\section{Materiais e procedimentos metodológicos}

Um levantamento microclimático da temperatura e umidade relativa do ar foi realizado em pontos dentro do campus da Universidade Federal de São Carlos (UFSCar), em duas campanhas de coletas de dados. Em seguida, os dados coletados foram submetidos a uma planilha eletrônica, para o tratamento estatístico.

Foi feita uma caracterização do entorno da UFSCar pela adoção de quatro parâmetros ou índices urbanísticos: FVC, CO, CVU, e dois CCS, separados entre permeável e impermeável (CCS P e CCS I, respectivamente).

Os dados térmicos e os dados relativos aos índices urbanísticos foram inseridos em um programa de RNA, para geração de um modelo preditivo. Nesse caso, aplicou-se o programa computacional EasyNN+, para averiguar a importância relativa dos elementos do entorno urbano sobre o ambiente térmico da UFSCar. Uma vez identificado o modelo preditivo, foi possível incorporá-lo a um SIG, o Quantum GIS, criando-se um algoritmo de cálculo para posterior desenvolvimento de um mapa temático representativo das condições térmicas de todo o campus. 


\section{Área delimitada como campo amostral}

No campus da UFSCar foram determinados pontos de coleta de dados térmicos. O campus se situa na cidade de São Carlos, que está localizada na região central do estado de São Paulo, entre as coordenadas $21^{\circ} 30^{\prime}$ e $22^{\circ} 30^{\prime}$ latitude sul e $47^{\circ} 30^{\prime}$ e $48^{\circ} 30^{\prime}$ longitude oeste. A altitude média do município é de $846 \mathrm{~m}$ acima do nível do mar, apresentando condições térmicas de inverno seco e verão chuvoso. A UFSCar situa-se em uma extensa área arborizada na zona periurbana e possui mais de $105 \mathrm{mil} \mathrm{m}^{2}$ de área construída.

A determinação dos locais de coleta dos dados térmicos levou em conta a possibilidade de diferentes situações amostrais de ocupação urbana, tais como:

(a) locais de passagem de pedestre com vegetação arbórea;

(b) locais de passagem de pedestre com vegetação arbustiva e rasteira; (c) locais de passagem de pedestre descampados e sem vegetação;

(d) locais de permanência com vegetação arbórea;

(e) locais de permanência descampados e sem vegetação;

(f) locais de passagem de pedestre em vias com edificação e vegetação; e

(g) locais de passagem de pedestre em vias com edificações e sem vegetação.

Foram realizadas coletas de dados em duas campanhas, para permitir maior cobertura amostral e visando um mapeamento térmico mais preciso de todo o campus. O número de pontos por coleta foi determinado em função do número de equipamentos disponíveis. A Figura 1 mostra a localização de São Carlos, o campus da UFSCar e os pontos de coleta dos dados térmicos nas duas campanhas.

\section{Figura 1 - Entorno urbano e pontos de coleta de dados}
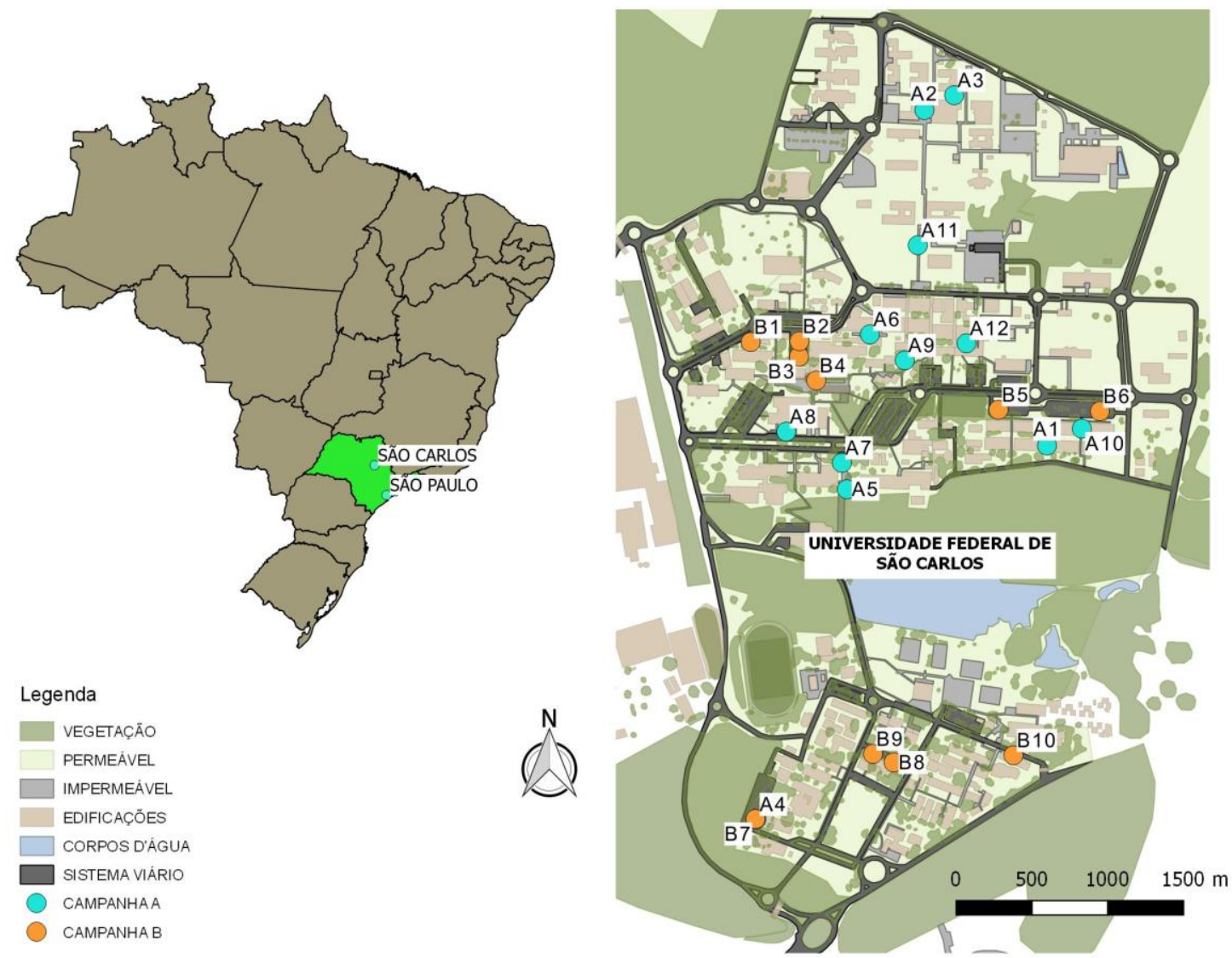

Fonte: adaptado a partir do Open Street Map (2015). 


\section{Coleta de dados}

Dados micrometeorológicos relacionados à temperatura do ar foram coletados para caracterizar o ambiente térmico da UFSCar. Para isso foram utilizados sensores digitais tipo data loggers (HOBO Pro V2 U23-001, com faixa de operação entre $-40{ }^{\circ} \mathrm{C}$ a $70{ }^{\circ} \mathrm{C}$, com índice de precisão de $0,2{ }^{\circ} \mathrm{C}$ acima de $0^{\circ} \mathrm{C}$ até $50{ }^{\circ} \mathrm{C}$, resolução de $0,02{ }^{\circ} \mathrm{C}$ a $25^{\circ} \mathrm{C}$ ), que foram fixados em postes de iluminação a 2,5 m do nível do solo. Os sensores HOBO foram devidamente equipados com escudos para proteção da radiação solar direta, recebendo também uma cobertura extra com material metálico reflexivo para evitar possíveis ganhos de calor de fontes luminosas artificiais

As duas campanhas de coleta de dados térmicos ocorreram durante o período de junho a agosto de 2014 (campanha A) e 2015 (campanha B), respectivamente. Dos dados coletados, um recorte amostral foi feito com base na análise visual de imagens de satélite e dados de cobertura de nuvens disponibilizados pela estação meteorológica do Instituto Nacional de Meteorologia (INMET). Para a criação das redes neurais, do conjunto de dados registrados hora a hora em todos os dias, foram considerados os dias de céu claro sem a influência da passagem de nuvens, ou seja, com nebulosidade abaixo de 0,5 décimos, ventos abaixo de $0,3 \mathrm{~m} / \mathrm{s}$ e com mais de $1,5^{\circ} \mathrm{C}$ de diferença entre os pontos de coleta.

As características climáticas dos dias de coleta, para as duas campanhas realizadas, corresponderam a uma temperatura média diária de $18,23^{\circ} \mathrm{C}$, média da umidade relativa de $68,3 \%$ e velocidade do vento média de $1,51 \mathrm{~m} / \mathrm{s}$. Os períodos resultantes para análise corresponderam a 29 dias, nos horários e características médias discriminados na Tabela 1.

\section{Índices urbanísticos}

Para levantar os parâmetros ou índices urbanísticos, um algoritmo foi desenvolvido dentro da plataforma de Sistema de Informação Geográfica Quantum GIS, para quantificar áreas dentro de um raio pré-estabelecido. Foram criadas camadas vetoriais do tipo polígonos com base em imagens de satélite e bases de dados Open Street Map (OSM) e Bing Map.

O programa computacional Quantum GIS V. 2.6 (Qgis) foi utilizado nesta pesquisa, pois é um software livre e, juntamente com o Open Source (código aberto), possibilita a criação de ferramentas com maior controle e domínio sobre as operações realizadas.

Para caracterizar os elementos do entorno urbano, foram extraídos os seguintes índices a respeito da:

(a) massa construída: para caracterizar a geometria urbana de acordo com a massa construída, foi extraído o $\mathrm{CO}$, obtido pela Equação 1:

$C O=\frac{\text { Áreaocupadaporedificios }}{\text { Areatotaldoraiodeabrangência }\left(\pi * R^{2}\right)} \quad$ Eq. 1

(b) vegetação urbana: o CVU foi utilizado para quantificar o valor da área do solo coberta por vegetação arbórea ou arbustiva, em relação à área do solo não vegetada. O CVU foi então expresso pela Equação 2:

$C V U=\frac{\text { Areacomvegetação }}{\text { Áreatotaldoraiodeabrangência }\left(\pi * R^{2}\right)} \quad$ Eq. 2

(c) revestimento do solo: o CCS foi extraído para quantificar o tipo de revestimento do solo, separando-se as áreas por características de permeabilidade. O CCSP quantificou as áreas naturais e permeáveis, e o CCSI quantificou as áreas impermeáveis e artificiais.

Esses índices foram expressos pelas Equações 3 e 4.

$$
\begin{array}{ll}
C C S P=\frac{\text { Árealivrepermeavél }}{\text { Áreatotaldoraiodeabrangência }\left(\pi * R^{2}\right)} & \text { Eq. } 3 \\
C C S I=\frac{\text { Árealivreimpermeavél }}{\text { Áreatotaldoraiodeabrangência }\left(\pi * R^{2}\right)} & \text { Eq. } 4
\end{array}
$$

O cálculo dos índices foi extraído a partir da construção de raios de abrangência de $25 \mathrm{~m}, 50 \mathrm{~m}$ e $100 \mathrm{~m}$ ao redor dos pontos de coleta térmica (Figura 2). Dentro desses raios foi então verificada a porcentagem relativa de áreas para o cálculo dos índices. O algoritmo desenvolvido realiza uma série de operações booleanas de borda e intersecção, que quantifica e relaciona a área total ocupada por cada parâmetro avaliado com a área total do lote.

Tabela 1 - Médias de temperatura e umidade, considerando as campanhas A e B, para a criação das redes neurais

\begin{tabular}{c|c|c|c|c}
\hline Período de horas & $\begin{array}{c}\text { Temperatura } \\
\text { média }\end{array}$ & $\begin{array}{c}\text { Temperatura } \\
\text { máxima }\end{array}$ & $\begin{array}{c}\text { Temperatura } \\
\text { mínima }\end{array}$ & $\begin{array}{c}\text { Umidade } \\
\text { relativa }\end{array}$ \\
\hline De 6 a 17 horas & 20,58 & 29,09 & 8,72 & $68,3 \%$ \\
De 18 a 5 horas & 15,99 & 23,04 & 9,14 & $68,4 \%$ \\
\hline
\end{tabular}


Figura 2 - Exemplo dos raios de abrangência para extração dos índices urbanísticos
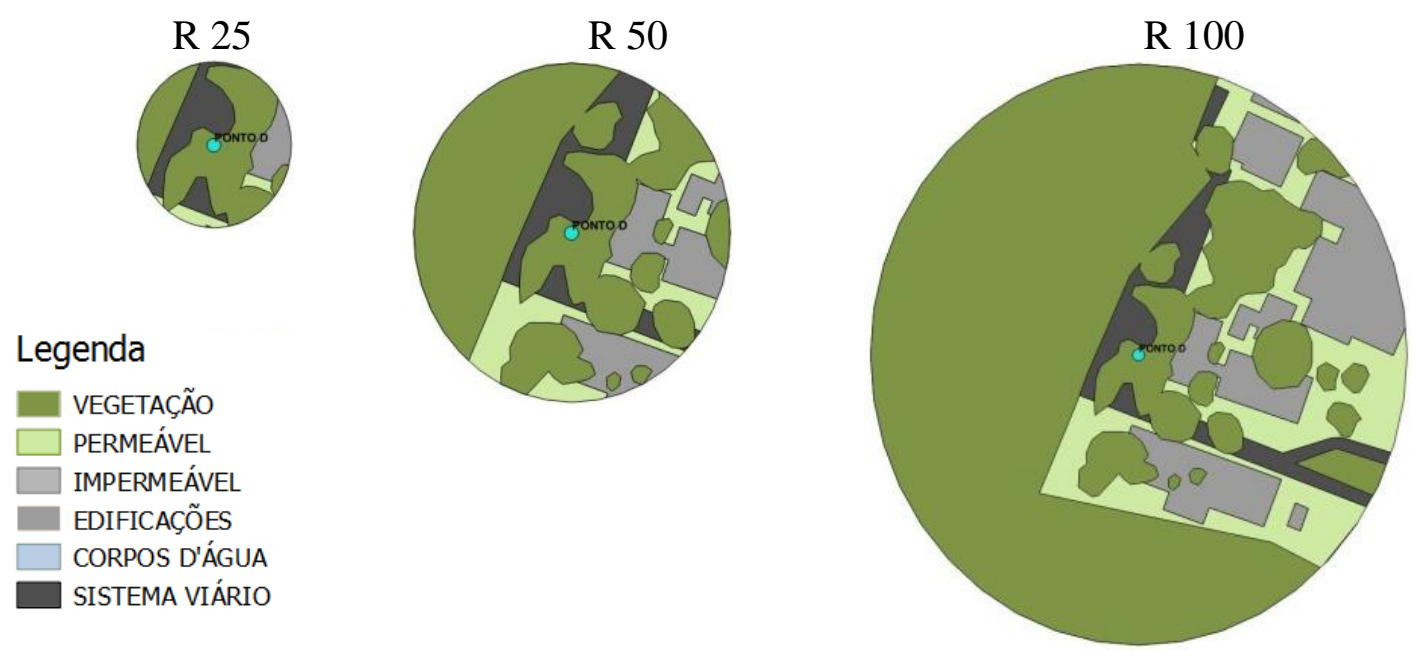

O FVC também foi obtido como índice para caracterizar a geometria urbana. O FVC foi determinado com auxílio de uma câmera digital equipada com lente tipo olho de peixe, com ângulo de visão de $180^{\circ}$ e posicionada exatamente no ponto de coleta dos dados. As imagens registradas para cada ponto foram tratadas digitalmente em preto e branco e submetidas ao software RAYMAN $\quad 1.2$ (MATZARAKIS; RUTZ; MAYER, 2010) para cálculo do FVC. A síntese da caracterização urbana pode ser observada na Tabela 2.

\section{Redes neurais artificiais}

O software EasyNN $+{ }^{1}$ foi utilizado para averiguar a importância relativa dos elementos do entorno urbano sobre o ambiente térmico, através do uso de RNA.

A aprendizagem da rede ocorre pela identificação de padrões de comportamento entre os dados de entrada e saída, gerando assim um modelo matemático representativo daquele padrão. $\mathrm{Na}$ prática, disponibilizou-se um conjunto de dados de entrada e saída, a partir dos quais o software utilizou uma parte para treinamento, outra parte para validação interna do modelo e outra parte para teste (Query). A proporção de distribuição adotada foi de $50 \%$ de dados para treinamento, $25 \%$ para validação e $25 \%$ para teste (Query).

Assim, os dados da campanha A, por representarem um número efetivamente maior de amostras, foram destinados ao desenvolvimento das redes. Esses corresponderam aos dados horários recortados a partir de todos os dias de medição e representando somente os períodos de

1Disponibilizado pelo Departamento de Engenharia de Transportes da Escola de Engenharia de São Carlos da Universidade de São Paulo. céu claro. Na inserção dos dados no software, os índices urbanísticos e as horas do dia corresponderam ao campo input (entrada de dados), e os dados sobre temperatura do ar corresponderam ao output (saída de dados).

Os dados foram ordenados aleatoriamente, verificando-se ainda que tanto o valor mínimo como o valor máximo de todas as variáveis fossem inseridos na fase de treinamento. Esse procedimento foi necessário para garantir que os valores simulados se encontrassem dentro da faixa de valores reais medidos.

Foram treinadas várias redes diferentes para cada raio de abrangência, dividindo-se os dados coletados de hora em hora em dois períodos: diurno (de 6 a 17 horas) e noturno (de 18 a 5 horas). Para teste de desempenho do modelo e seleção das redes neurais de melhor desempenho, foram utilizados os valores do coeficiente de correlação (R) e os erros relativos, gerados pela comparação entre dados reais e dados simulados.

Complementarmente, os dados da campanha B foram submetidos à comparação com os dados simulados pelos modelos de melhor desempenho, para uma nova validação daqueles modelos e posterior desenvolvimento de mapas térmicos. Após validação, as redes foram incorporadas no Quantum, gerando um modelo de previsão de temperatura. Esse algoritmo pôde ser então aplicado a outros pontos do campus para os quais não se contava com as medições, para a criação de valores de temperatura, a partir dos índices urbanísticos daqueles novos pontos.

Dessa forma, com uma grade de valores térmicos (reais e simulados) gerada para todo o campus, foi possível promover a interpolação de dados dentro do SIG e criar mapas térmicos. 


\section{Resultados e análise}

Após o treinamento e o teste Query de todas as redes preparadas, as redes mais precisas de cada raio de abrangência foram separadas para análise da importância relativa em função da escala adotada. Todas as redes treinadas apresentaram bom desempenho nos testes de correlação entre as temperaturas reais e aquelas simuladas. A Tabela 3 ilustra o resultado do teste de correlação e os erros relativos, médios e máximos, para as redes de melhor desempenho, para cada raio de abrangência.

A Tabela 3 indica que o desempenho das redes selecionadas é muito similar, quando considerados o coeficiente de correlação e o erro relativo. No entanto, para o período diurno, se observado o conjunto de todos os parâmetros de desempenho, a rede criada para o raio de abrangência de $25 \mathrm{~m}$ apresentou-se ligeiramente mais precisa. No caso do período noturno, os coeficientes de correlação foram um pouco menores do que o diurno, mas a rede para o raio de $100 \mathrm{~m}$ apresentou um desempenho um pouco melhor. Acredita-se que o menor desempenho da rede noturna esteja relacionado à própria complexidade do processo de evapotranspiração dos elementos vegetais, uma vez que o campus em análise está inserido em uma ampla área de vegetação.

Tabela 2 - Síntese da caracterização do entorno urbano para os três raios de abrangência

\begin{tabular}{|c|c|c|c|c|c|c|c|c|c|c|c|c|c|c|}
\hline \multirow{14}{*}{ 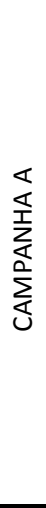 } & & & \multicolumn{4}{|c|}{25 METROS } & \multicolumn{4}{|c|}{50 METROS } & \multicolumn{4}{|c|}{100 METROS } \\
\hline & PONTO & FVC & $\mathrm{CO}$ & CVU & CCS P & CCSI & $\mathrm{CO}$ & CVU & CCS P & CCSI & $\mathrm{CO}$ & CVU & $\operatorname{CCS} P$ & CCSI \\
\hline & $\mathrm{A} 1$ & 0.32 & 0.46 & 0.16 & 0.54 & 0.01 & 0.41 & 0.26 & 0.51 & 0.09 & 0.21 & 0.35 & 0.57 & 0.22 \\
\hline & $\mathrm{A} 2$ & 0.58 & 0.43 & 0.01 & 0.32 & 0.23 & 0.38 & 0.00 & 0.47 & 0.16 & 0.27 & 0.01 & 0.56 & 0.18 \\
\hline & A3 & 0.47 & 0.55 & 0.01 & 0.41 & 0.04 & 0.44 & 0.01 & 0.51 & 0.06 & 0.24 & 0.08 & 0.50 & 0.18 \\
\hline & A4 & 0.18 & 0.15 & 0.63 & 0.17 & 0.69 & 0.18 & 0.65 & 0.51 & 0.31 & 0.14 & 0.71 & 0.74 & 0.13 \\
\hline & A5 & 0.22 & 0.02 & 0.65 & 0.45 & 0.51 & 0.20 & 0.54 & 0.63 & 0.19 & 0.18 & 0.53 & 0.65 & 0.18 \\
\hline & A6 & 0.65 & 0.58 & 0.03 & 0.24 & 0.17 & 0.48 & 0.08 & 0.42 & 0.12 & 0.37 & 0.11 & 0.54 & 0.09 \\
\hline & A7 & 0.53 & 0.12 & 0.42 & 0.62 & 0.26 & 0.17 & 0.37 & 0.51 & 0.33 & 0.16 & 0.45 & 0.58 & 0.25 \\
\hline & A8 & 0.56 & 0.21 & 0.14 & 0.43 & 0.35 & 0.29 & 0.16 & 0.42 & 0.30 & 0.26 & 0.26 & 0.41 & 0.30 \\
\hline & A9 & 0.32 & 0.38 & 0.18 & 0.51 & 0.09 & 0.30 & 0.21 & 0.52 & 0.19 & 0.32 & 0.24 & 0.46 & 0.22 \\
\hline & A10 & 0.28 & 0.44 & 0.06 & 0.37 & 0.19 & 0.41 & 0.09 & 0.29 & 0.31 & 0.17 & 0.18 & 0.56 & 0.27 \\
\hline & A11 & 0.81 & 0.01 & 0.01 & 0.86 & 0.13 & 0.14 & 0.00 & 0.78 & 0.09 & 0.12 & 0.03 & 0.49 & 0.11 \\
\hline & A12 & 0.62 & 0.69 & 0.01 & 0.29 & 0.02 & 0.45 & 0.15 & 0.48 & 0.07 & 0.30 & 0.17 & 0.46 & 0.23 \\
\hline \multirow{12}{*}{ 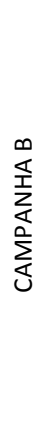 } & & & \multicolumn{4}{|c|}{25 METROS } & \multicolumn{4}{|c|}{50 METROS } & \multicolumn{4}{|c|}{100 METROS } \\
\hline & PONTO & FVC & CCS P & CCSI & $\mathrm{CO}$ & CVU & $\mathrm{CO}$ & CVU & CCS P & $\operatorname{CCSI}$ & $\mathrm{CO}$ & CVU & $\operatorname{CCS} P$ & CCSI \\
\hline & B1 & 0.29 & 0.44 & 0.36 & 0.21 & 0.19 & 0.25 & 0.23 & 0.49 & 0.28 & 0.23 & 0.25 & 0.47 & 0.30 \\
\hline & B2 & 0.21 & 0.35 & 0.57 & 0.10 & 0.60 & 0.21 & 0.41 & 0.38 & 0.42 & 0.28 & 0.25 & 0.44 & 0.30 \\
\hline & B3 & 0.50 & 0.49 & 0.35 & 0.17 & 0.61 & 0.31 & 0.43 & 0.38 & 0.31 & 0.32 & 0.26 & 0.39 & 0.32 \\
\hline & B4 & 0.21 & 0.17 & 0.59 & 0.35 & 0.42 & 0.39 & 0.33 & 0.35 & 0.34 & 0.31 & 0.30 & 0.45 & 0.27 \\
\hline & B5 & 0.28 & 0.35 & 0.57 & 0.10 & 0.34 & 0.17 & 0.33 & 0.43 & 0.41 & 0.20 & 0.28 & 0.52 & 0.29 \\
\hline & B6 & 0.69 & 0.22 & 0.75 & 0.04 & 0.15 & 0.15 & 0.11 & 0.42 & 0.45 & 0.15 & 0.05 & 0.58 & 0.28 \\
\hline & B7 & 0.18 & 0.18 & 0.71 & 0.13 & 0.64 & 0.17 & 0.66 & 0.53 & 0.31 & 0.14 & 0.71 & 0.74 & 0.13 \\
\hline & B8 & 0.34 & 0.38 & 0.28 & 0.35 & 0.28 & 0.23 & 0.30 & 0.53 & 0.25 & 0.21 & 0.23 & 0.56 & 0.24 \\
\hline & B9 & 0.51 & 0.40 & 0.30 & 0.31 & 0.33 & 0.22 & 0.25 & 0.52 & 0.27 & 0.23 & 0.22 & 0.54 & 0.24 \\
\hline & B10 & 0.45 & 0.45 & 0.19 & 0.37 & 0.21 & 0.32 & 0.19 & 0.52 & 0.17 & 0.24 & 0.32 & 0.47 & 0.19 \\
\hline
\end{tabular}

Tabela 3 - Resultado da análise de correlação e erro relativo das redes escolhidas

\begin{tabular}{|c|c|c|c|c|c|}
\hline & \multicolumn{5}{|c|}{25 METROS } \\
\hline & CORRELAÇÃO & ERRO RELATIVO & ERRO RELATIVO MÁX & ERRO MÉDIO & ERRO MÁXIMO \\
\hline DIA $06: 00$ às $17: 00$ horas & 0.92 & $8 \%$ & $43 \%$ & 1.59 & 6.14 \\
\hline \multirow[t]{3}{*}{ NOITE $18: 00$ às $05: 00$ horas } & 0.75 & $8 \%$ & $47 \%$ & 1.23 & 5.98 \\
\hline & \multicolumn{5}{|c|}{50 METROS } \\
\hline & CORRELAÇÃO & ERRO RELATIVO & ERRO RELATIVO MÁX & ERRO MÉDIO & ERRO MÁXIMO \\
\hline DIA 06:00 às $17: 00$ horas & 0.91 & $9 \%$ & $51 \%$ & 1.56 & 5.8 \\
\hline \multirow[t]{3}{*}{ NOITE $18: 00$ às $05: 00$ horas } & 0.74 & $9 \%$ & $39 \%$ & 1.43 & 6.18 \\
\hline & \multicolumn{5}{|c|}{50 METROS } \\
\hline & CORRELAÇÃO & ERRO RELATIVO & ERRO RELATIVO MÁX & ERRO MÉDIO & ERRO MÁXIMO \\
\hline DIA 06:00 às $17: 00$ horas & 0.92 & $8 \%$ & $63 \%$ & 1.53 & 6.34 \\
\hline NOITE $18: 00$ às $05: 00$ horas & 0.76 & $8 \%$ & $45 \%$ & 1.21 & 5.07 \\
\hline
\end{tabular}




\section{Importância relativa em função da escala de abrangência}

Para todas as redes apresentadas anteriormente na Tabela 3, foi ainda observado que a contribuição relativa dos parâmetros urbanos sobre a temperatura do ar mudou, de acordo com o período e escala de análise adotada (Figura 3).

Mais uma vez a influência da vegetação sobre o ambiente térmico do campus pode ser destacada. $\mathrm{O}$ CVU, variável relacionada ao percentual de vegetação, foi um dos índices mais importantes nos modelos das diversas escalas de abrangência ( $25 \mathrm{~m}, 50 \mathrm{~m}$ e $100 \mathrm{~m})$. Quando se comparam todas as variáveis, para os diversos modelos, observa-se que o CVU assume posição mais relevante nos modelos para os raios de $25 \mathrm{~m}$ e $50 \mathrm{~m}$ e segunda posição para o raio de $100 \mathrm{~m}$. Dessa forma, verifica-se que o CVU é um índice urbanístico com potencial para ser utilizado como instrumento quantitativo do ambiente térmico.

O CCS P também demonstrou esse potencial, atingindo importância relativa significativa dentre os modelos. Com exceção do comportamento apresentado para o raio de $100 \mathrm{~m}$ durante o dia, os resultados mostram que o CCS $\mathrm{P}$ se torna mais importante à medida que o raio de abrangência aumenta. Este é um índice ligado à permeabilidade do solo, e, portanto, funciona como regulador de penetração de água no solo, colaborando, consequentemente, na estabilidade térmica da superfície. Sua importância parece ser mais significativa durante o período noturno.

Os demais índices (CCS I, FVC e CO), apesar de se constituírem como importantes variáveis dos modelos, tendem a apresentar valores mais similares entre si. Uma exceção é o CCS I para o modelo do período diurno com raio de $100 \mathrm{~m}$, que se tornou mais relevante do que o próprio CVU. Essa característica revela o impacto causado pelas superfícies impermeáveis, mesmo em áreas com grande disponibilidade de vegetação.

Cabe ainda salientar que o CO, que é um índice comumente aplicado por órgãos gestores, tem um comportamento mais estável entre o dia e a noite. No entanto, parece ser um índice um pouco mais limitado para fins térmicos, uma vez que sua importância relativa apresentou médias mais baixas entre as variáveis dos modelos.

O FVC, por sua vez, apesar de ter alcançado algumas vezes valores mais baixos, tendeu a ser mais relevante à medida que se aumentou o raio de abrangência considerado nos modelos diurnos. Nos modelos noturnos, somente para o raio de 100 $\mathrm{m}$ é que o FVC assumiu valores mais significativos.

\section{Sensibilidade dos modelos para parâmetros urbanísticos em relação ao raio de abrangência}

A análise de sensibilidade dos modelos foi realizada a partir de simulações dentro das redes de melhor desempenho. Fixaram-se os valores das médias de cada variável, considerando-se especificamente os horários das $14 \mathrm{~h}$ para o dia e das $21 \mathrm{~h}$ para a noite (horários com diferenças térmicas mais significativas entre os pontos do campus). Foi possível verificar o padrão de temperatura gerado por cada modelo, em relação a cada índice urbanístico e raio de abrangência. As Figuras 4 a 13 mostram a análise de sensibilidade para os parâmetros urbanísticos do FVC, CO, CVU, CCS P e CCS I, respectivamente.

Para o raio de $25 \mathrm{~m}$, a variação de temperatura dada em função do FVC foi insignificante, mantendo-se estável nos dois períodos analisados. Para os raios de $50 \mathrm{~m} \mathrm{e} 100 \mathrm{~m}$, a temperatura do ar variou em média $-2,5{ }^{\circ} \mathrm{C}$ às $14 \mathrm{~h}$ (Figura 4), e $+1,25^{\circ} \mathrm{C}$ às $21 \mathrm{~h}$ (Figura 5). Analisando-se os padrões, observa-se que se trata de um comportamento específico para os horários de análise. Durante o dia, com a implantação esparsa de edificações em meio à grande área de vegetação, o maior FVC nos modelos de $50 \mathrm{~m} \mathrm{e}$ $100 \mathrm{~m}$ confere menores temperaturas ao ar, por possibilitar a maior permeabilidade dos ventos. Esse comportamento se inverte à noite, no horário das $21 \mathrm{~h}$, porque as superfícies que receberam maior incidência da radiação solar durante o dia ainda estão liberando o calor armazenado e, consequentemente, aquecendo o ar adjacente. Os modelos parecem, portanto, apresentar respostas coerentes.

Sobre o CO (Figuras 6 e 7), observou-se que, para as $14 \mathrm{~h}$, nos raios de $25 \mathrm{~m}$ e $50 \mathrm{~m}$, a curva de temperatura do ar variou negativamente, em média $-2,0{ }^{\circ} \mathrm{C}$, enquanto para $\mathrm{o}$ raio de $100 \mathrm{~m} \mathrm{a}$ temperatura do ar manteve-se um pouco mais estável. Esse fato indica que o CO perde a sua significância térmica para escalas mais abrangentes durante o dia. Por outro lado, para 25 m e $50 \mathrm{~m}$, a maior ocupação está relacionada ao maior número de superfícies sombreadas, por isso acredita-se que o aumento do CO tenha provocado menores temperaturas do ar. No entanto, às $21 \mathrm{~h}$ com o raio de $50 \mathrm{~m}$, o modelo parece apresentar padrões mais instáveis, com um crescimento abrupto de temperatura, quando o $\mathrm{CO}$ é maior que 0.31 . 
Figura 3 - Importância relativa dos parâmetros urbanos em relação à escala de análise

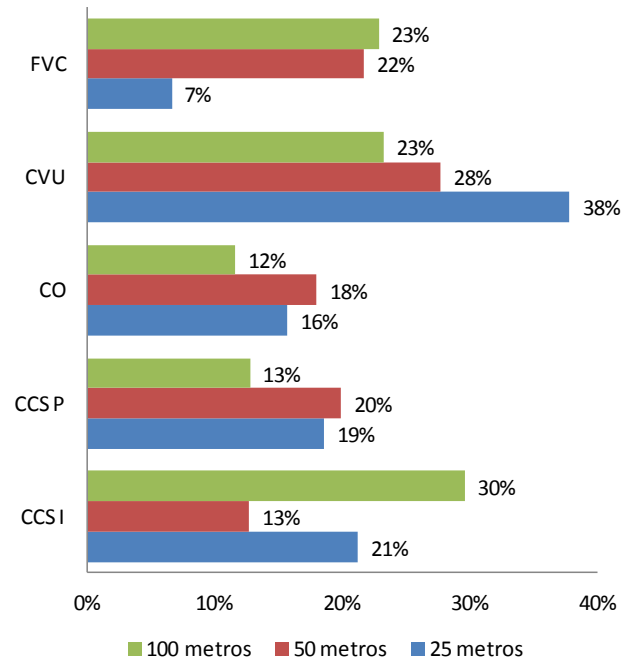

(a) Dia (Das 6 às 17 horas)

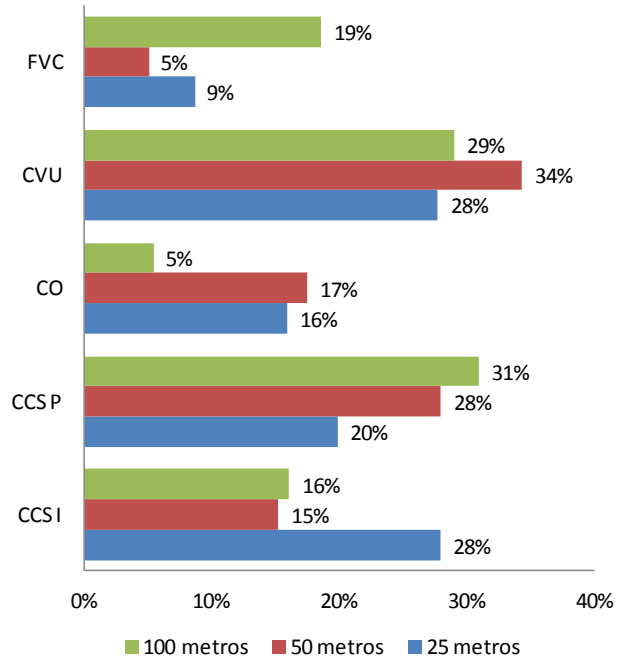

(b) Noite (Das 18 às 5 horas)

Figura 4 - Sensibilidade FVC - 14h
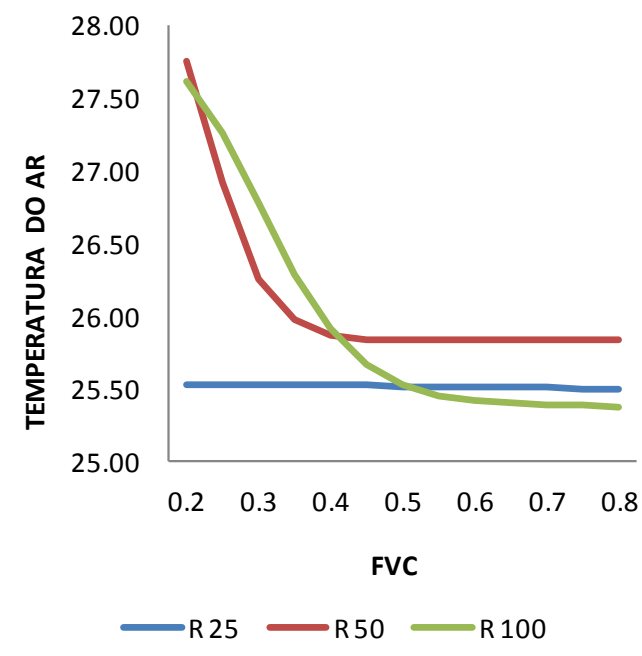

Figura 5 - Sensibilidade FVC - 21h
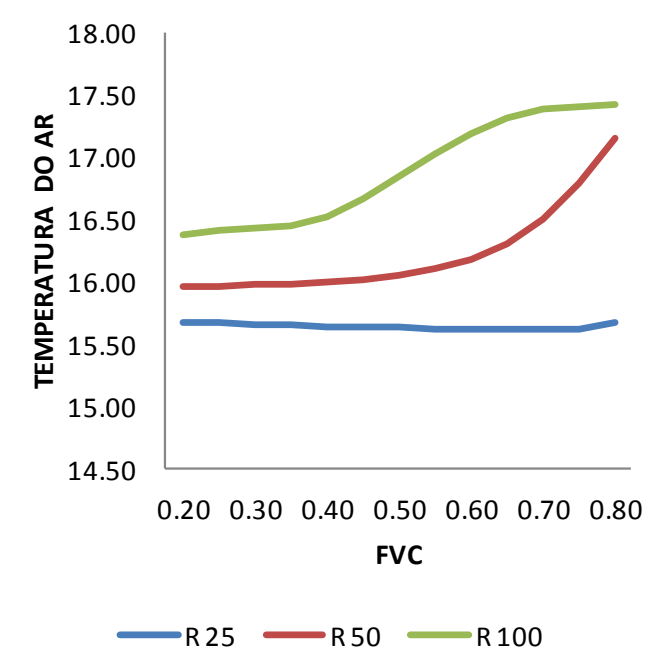
Figura 6 - Sensibilidade CO - 14h

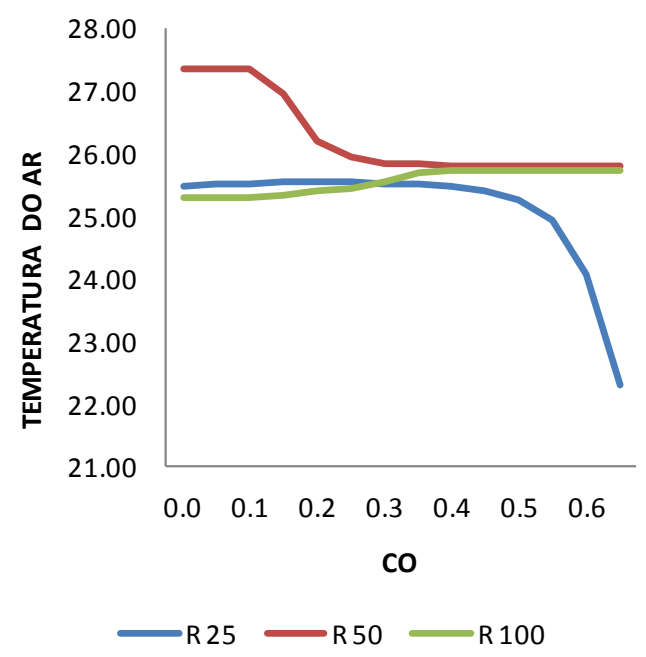

Figura 7 - Sensibilidade CO - $21 \mathrm{~h}$

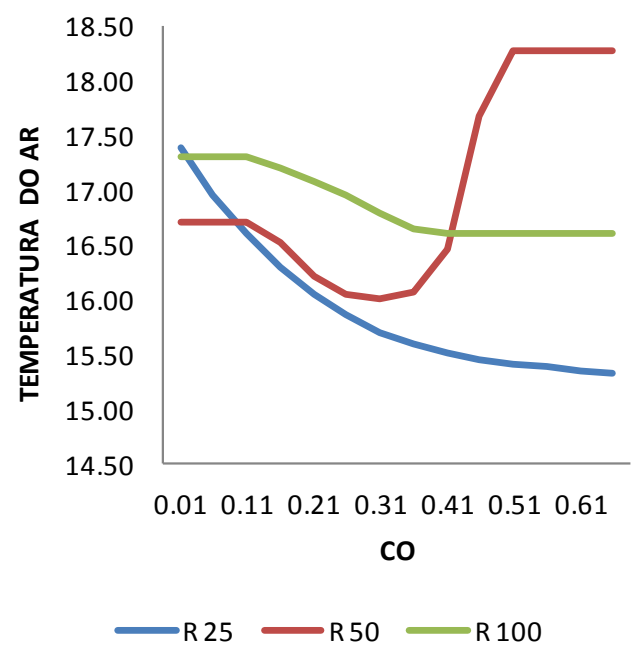

A sensibilidade do CVU (Figuras 8 e 9) apontou comportamento decrescente para a temperatura do ar no raio de $25 \mathrm{~m}$, de cerca de $-4,0^{\circ} \mathrm{C}$ às $14 \mathrm{~h}$. Para os raios de $50 \mathrm{~m}$ e $100 \mathrm{~m}$, a variação de temperatura do ar foi muito discreta e, apesar da análise de importância relativa ter indicado a relevância da variável, não se pode afirmar que o modelo tenha gerado variação de temperatura em função do CVU. No entanto, às $21 \mathrm{~h}$, todos os raios de abrangência apresentaram curva decrescente de temperatura do ar em função do CVU. A maior contribuição foi percebida para o raio de $100 \mathrm{~m}$, que variou cerca de $-3{ }^{\circ} \mathrm{C}$.

Em relação ao $\mathrm{CCP} S$, no período diurno e noturno, o modelo para o raio de $50 \mathrm{~m}$ se comporta novamente diferente dos demais, com decréscimos ou acréscimos muito bruscos. Os modelos de $25 \mathrm{~m}$ e $100 \mathrm{~m}$, no entanto, mostram-se mais estáveis e coerentes entre si. Para o período noturno, os resultados dos modelos de $25 \mathrm{~m}$ e $100 \mathrm{~m}$ são mais significativos, mostrando a capacidade de decréscimo da temperatura do ar, à medida que se aumenta o valor de CCP S.

A variação do CCS I não apresenta influência no modelo de $50 \mathrm{~m}$ para o período diurno, e, para o mesmo raio no período noturno, o modelo apresenta tendência inversa àquela apresentada pelos demais. De uma forma geral, a análise dessa variável específica parece ser mais coerente com a realidade quando considerado o modelo de raio de $100 \mathrm{~m}$ no período diurno. Nesse caso, a temperatura tende a subir à medida que a porcentagem de superfícies impermeáveis aumenta. 
Figura 8 - Sensibilidade CVU - às $14 \mathrm{~h}$
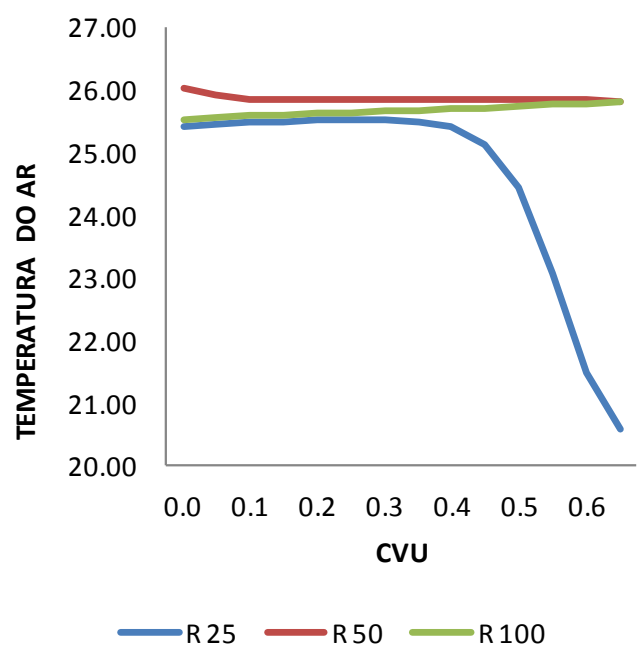

Figura 9 - Sensibilidade CVU - às $21 \mathrm{~h}$
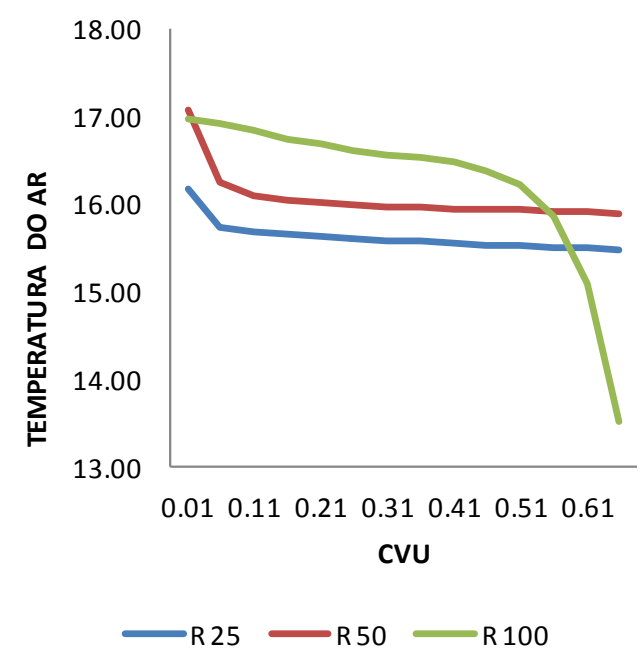

Figura 10 - Sensibilidade CCS P às $14 \mathrm{~h}$

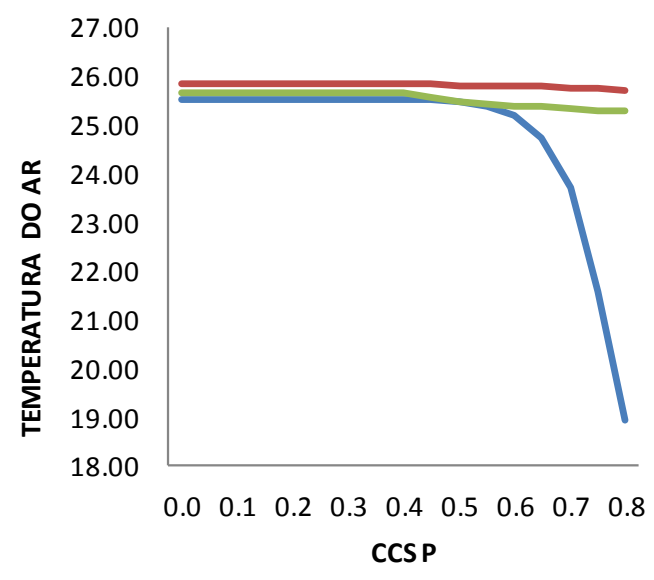

$\longrightarrow R 25=R 50=R 100$ 
Figura 11 - Sensibilidade CCS P às $21 \mathrm{~h}$
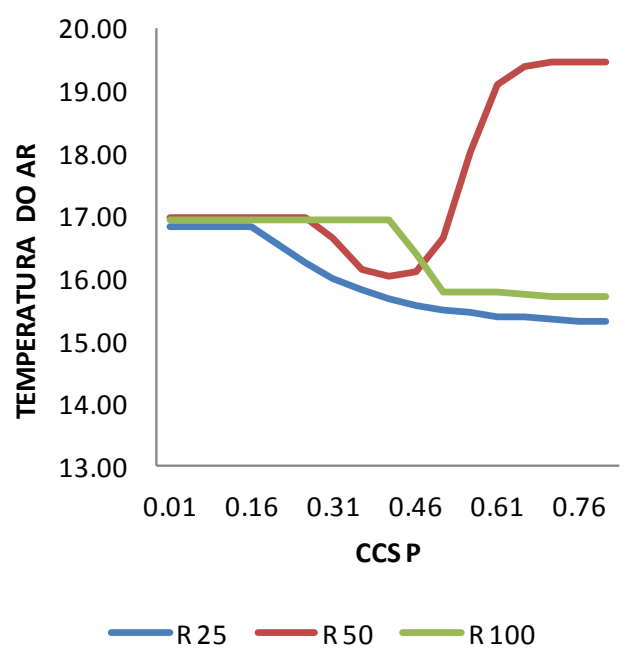

Figura 12 - Sensibilidade CCS I às $14 \mathrm{~h}$
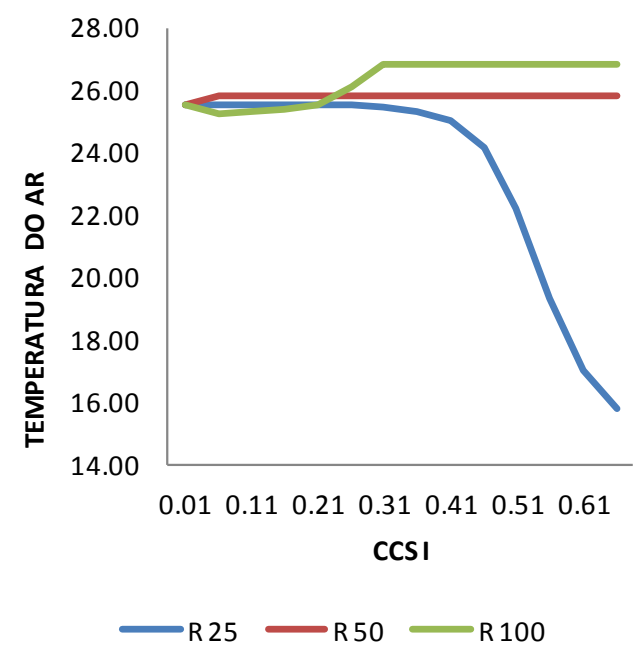

Figura 13 - Sensibilidade CCS I às $21 \mathrm{~h}$

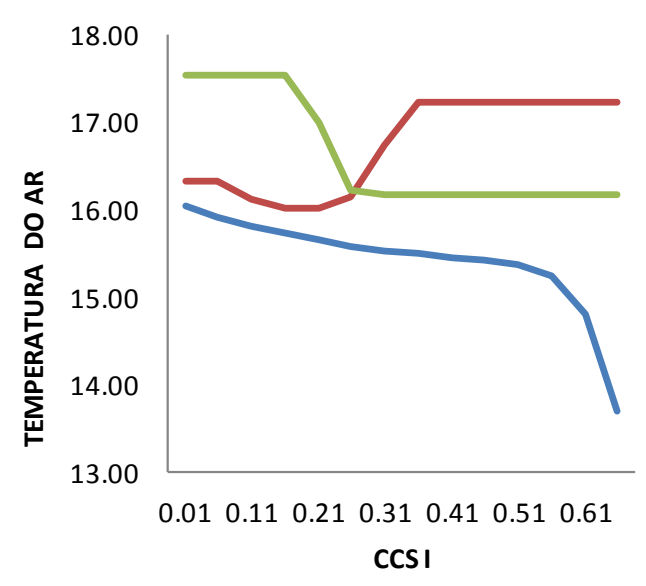

$\longrightarrow \mathrm{R} 25-\mathrm{R} 50=\mathrm{R} 100$ 


\section{Análise do ambiente térmico e aplicação do modelo}

Observadas as limitações apresentadas no teste de sensibilidade, verificam-se duas redes que parecem responder mais adequadamente às condições térmicas apresentadas pelo campus da UFSCar: a rede correspondente ao raio de $25 \mathrm{~m}$ para o período diurno e ao de $100 \mathrm{~m}$ para o período noturno.

As Figuras 14 e 15 representam as respectivas correlações entre dados medidos e simulados com essas redes.

Para validar a aplicação dos modelos escolhidos, os dados térmicos e os parâmetros urbanos da campanha $\mathrm{B}$ foram distribuídos aleatoriamente e posteriormente submetidos à simulação com as redes selecionadas. Repetindo-se o procedimento de validação anterior, os dados simulados para temperatura do ar foram então relacionados com os dados reais medidos em campo. O coeficiente de correlação foi obtido para validação dos modelos.

Para os dados do dia, o modelo proposto se mostrou adequado, com coeficiente de correlação de $\mathrm{R}=0,93$. Para a noite, no entanto, o modelo não obteve bons resultados e não foi possível validar os dados simulados. As Figuras 16 e 17 ilustram a validação dos dados reais e simulados para a campanha B, a partir da análise de correlação.

Os resultados obtidos pelo teste de validação apontam que os parâmetros urbanos elencados para avaliar o ambiente térmico nesta pesquisa se relacionaram melhor com as temperaturas diurnas. É preciso, assim, futuramente repetir a metodologia com a criação de novas redes para o período noturno, elencando novos índices térmicos e urbanísticos.

Figura 14 - Correlação entre real e simulado para período diurno com raio de 25 m

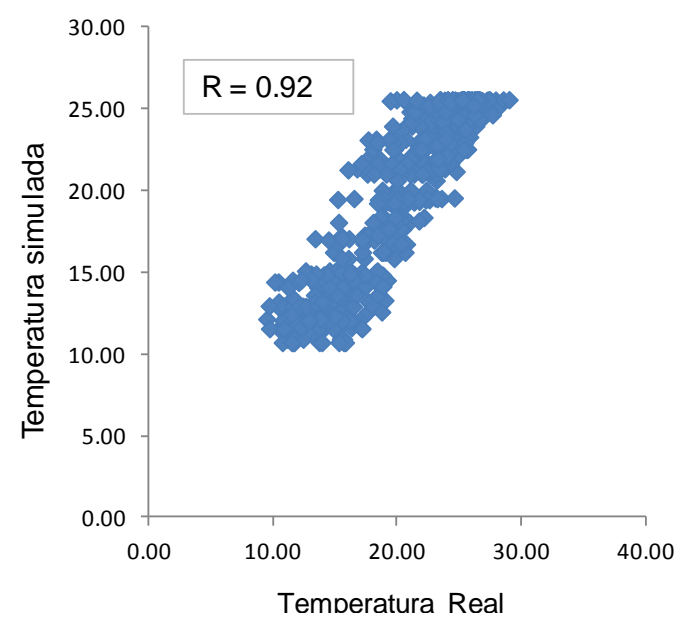

Figura 15 - Correlação entre real e simulado para período noturno com raio de $100 \mathrm{~m}$

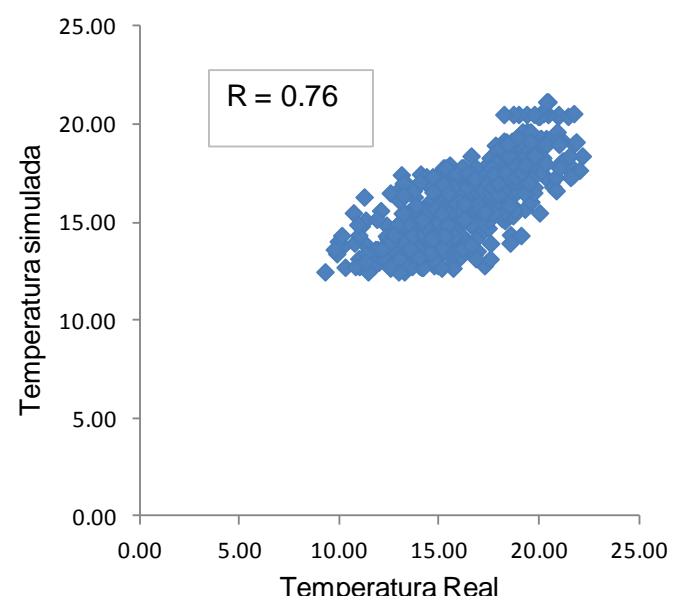


Figura 16 - Validação da simulação para o dia

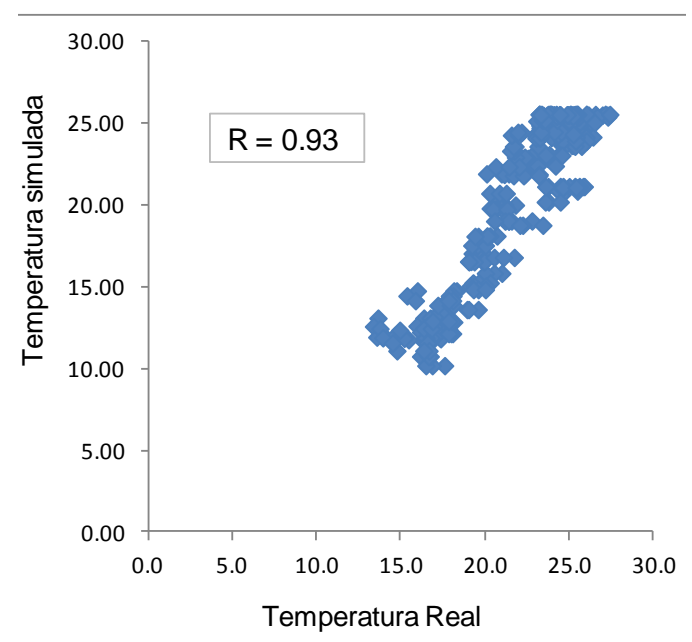

Figura 17 - Validação da simulação para a noite

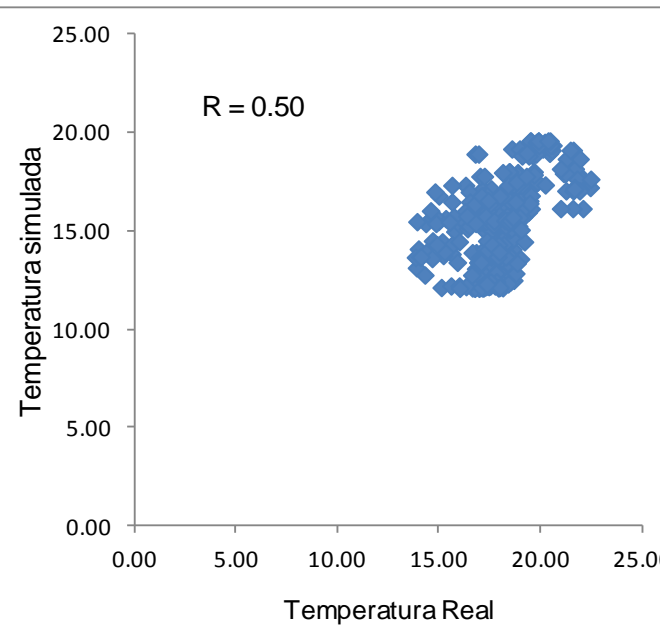

A configuração de ocupação do campus, muito arborizada e com predominância do solo natural do tipo gramínea, favorece a criação de bolsões térmicos em razão do comportamento natural da vegetação, que eleva as taxas de umidade do ar. Assim, conforme mencionado anteriormente, o efeito da evapotranspiração sobre a temperatura do ar pode ter contribuído para o fraco desempenho do modelo durante a noite, e necessita maiores investigações.

\section{Aplicação do modelo na criação de mapas térmicos}

Após o teste de validação, o modelo diurno foi utilizado para criação de mapas temáticos do ambiente térmico da UFSCar. O resultado pode ser observado nas Figuras 18 e 19, que mostram a comparação de um mapa temático criado pelo método de interpolação de peso pelo inverso da distância (IDW), a partir de dados térmicos reais de doze (12) pontos de coleta e dados térmicos para vinte e dois (22) pontos simulados.

A partir da comparação dos mapas, foi possível notar que o mapa criado com os dados simulados descreve com mais detalhe o ambiente térmico, por contar mais pontos espalhados pelo campus. A quantidade de pontos utilizados para a criação dos mapas térmicos está diretamente associada à precisão desejada. Assim, o resultado dos mapas temáticos pode ser melhorado, adicionando-se novos pontos para simulação com o modelo proposto.

O mapa simulado permitiu observar que os pontos mais quentes se concentraram nas áreas mais ocupadas da UFSCar, e que as zonas de frescor se localizaram sobre massas de vegetação ou áreas livres, pavimentadas ou não. 


\section{Discussões}

Os resultados obtidos nesta pesquisa apontam que o microclima nos ambientes externos construídos experimenta influência significativa dos parâmetros do entorno urbano, sofrendo variação de temperatura de um local para outro, devido à configuração e disposição dos edifícios, das vias e da vegetação. Resultados semelhantes foram apontados por Dimoudi et al. (2013) e Shahrestani et al. (2015), que enfatizam a importância de se considerar aqueles parâmetros para a avaliação e o planejamento do ambiente urbano.

Figura 18 - Mapa térmico - 2 dados reais

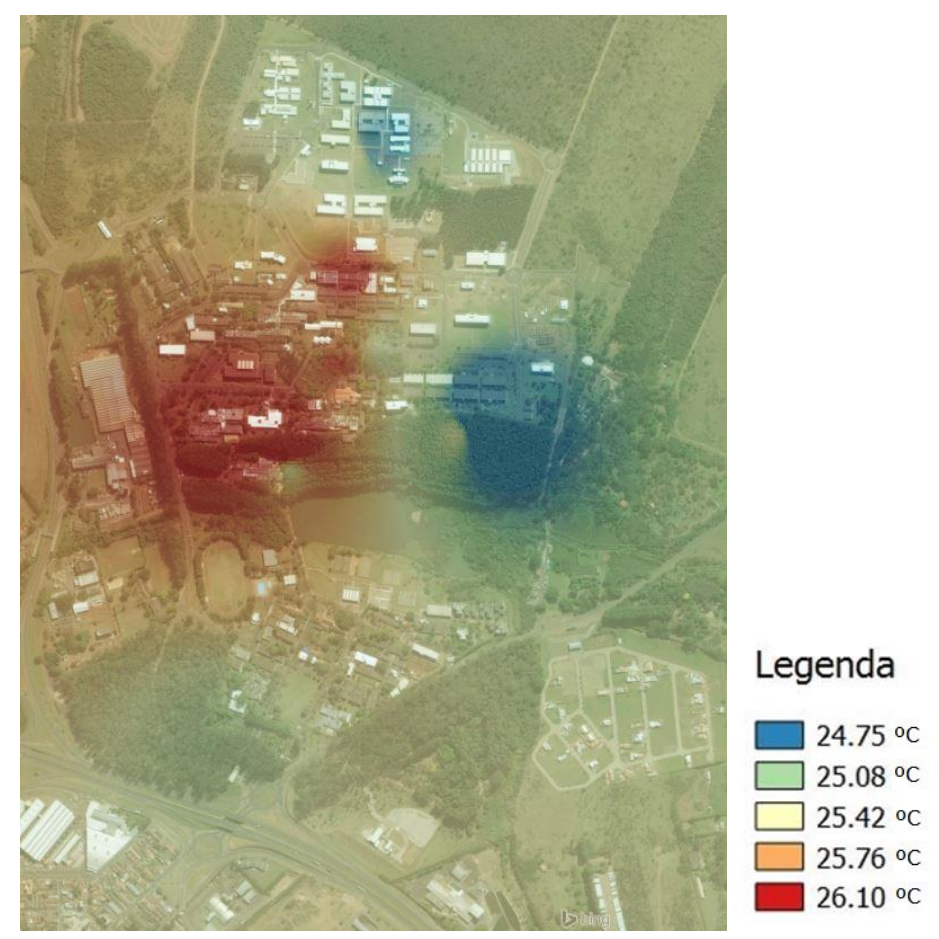

Figura19 - Mapa térmico -3 dados simulados

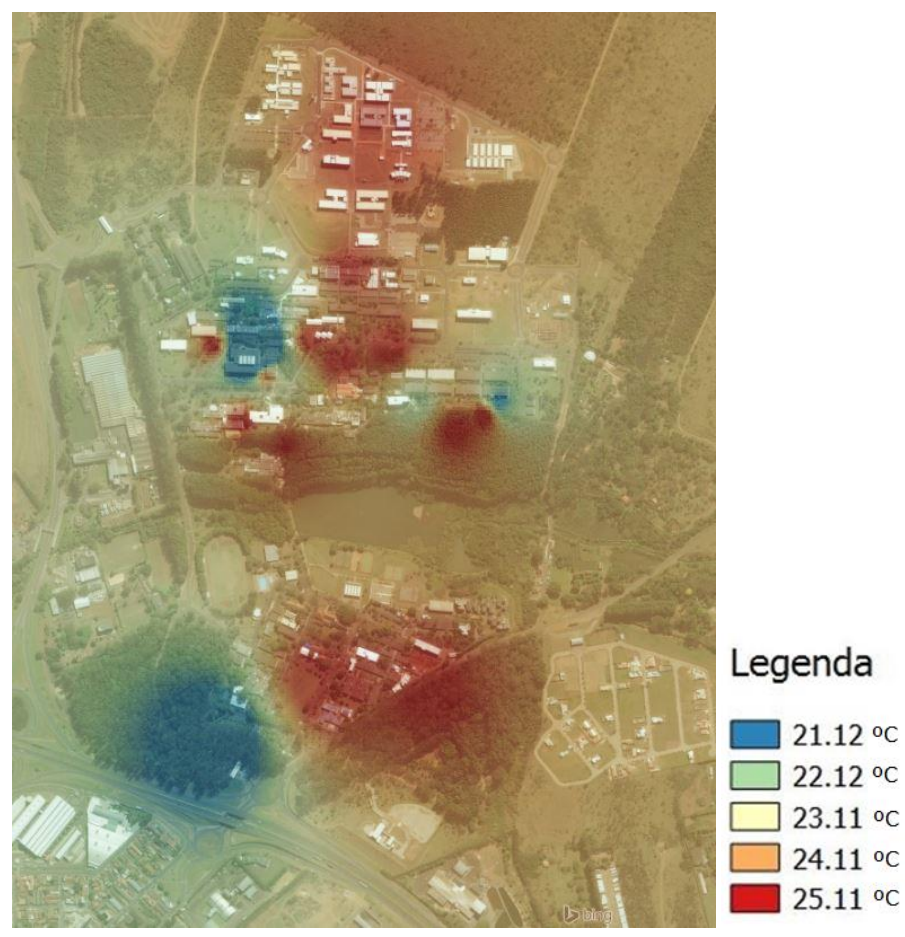


Porém, a análise da influência da configuração e da disposição urbana sobre o ambiente térmico requer uma clara definição sobre a escala de abordagem. A partir dos resultados aqui alcançados, verificou-se influência mais significativa, quando considerado o raio de $25 \mathrm{~m}$ de abrangência. $O$ estudo de Houet e Pigeon (2011) para Toulouse, na França, reforça esse aspecto, quando conclui que o ambiente climático, ao ser avaliado em escalas menores, apresenta diferenças de temperatura mais significativas do que aquelas observadas em escalas mais amplas.

No entanto, mesmo para o maior raio aqui estudado houve influência das características do entorno urbano sobre $\mathrm{o}$ ambiente térmico. Similarmente, Wong et al. (2016) utilizaram raio de $100 \mathrm{~m}$ para relacionar fatores microclimáticos locais e os parâmetros do entorno urbano, com auxílio de uma plataforma SIG, e também encontraram boas relações empíricas entre o entorno urbano e a temperatura do ar. Esse fato reforça que a variação do clima intraurbano é resultado da complexa interação entre os parâmetros urbanísticos e os fatores meteorológicos locais.

Dentre os parâmetros estudados, pela própria característica vegetativa do campus universitário, cabe ainda ressaltar o papel do CVU como instrumento na tomada de decisões para a amenização das temperaturas. Esse índice teve influência térmica significativa em todas as escalas de abrangência. Nas menores escalas, observou-se que o aumento de CVU pode reduzir as temperaturas máximas durante o dia. De uma forma geral, para o planejamento climático do ambiente construído, o aumento do CVU deve ser compreendido como o aumento de maciços arbóreos, mais do que simplesmente o plantio de árvores esparsas. Como destacam Hien e Jusuf (2010), em sua pesquisa para Singapura, a presença de maciços de vegetação tende a ser termicamente mais eficiente do que árvores espaçadas no alinhamento dos passeios e vias, pois proporciona arrefecimento evapotranspirativo.

Por fim, destaca-se ainda que a metodologia aplicada neste estudo pode servir de subsídios para a criação de ferramentas e estratégias de mitigação e adaptação climática de áreas urbanas. O uso do SIG em associação com as RNA possibilitou o desenvolvimento de mapas térmicos, o que contribuiu para a melhor compreensão da interação relativa dos parâmetros do entorno coma temperatura do ar. Mapas térmicos criados em plataforma SIG também foram desenvolvidos por Chen e Ng (2011), com base em indicadores de ocupação urbana e o FVC. Reforçando o potencial aqui apontado por esse instrumento, aqueles autores também verificaram boa relação entre os índices estudados e as temperaturas observadas nos mapas.

\section{Conclusão}

Este artigo investigou a contribuição relativa dos parâmetros do entorno urbano sobre o ambiente térmico de um campus universitário na cidade de São Carlos, identificando que o CVU é o índice urbanístico mais significativo na determinação dos padrões térmicos daquele local.

A aplicação de RNA para a criação de um modelo de previsão e sua incorporação em uma plataforma SIG possibilitou o desenvolvimento de mapas térmicos a partir de parâmetros urbanísticos do local. Esses mapas temáticos, por sua vez, compreendem informações úteis para o apoio à decisão e, utilizados como instrumentos de previsão e avaliação de cenários futuros, podem ainda contribuir para o planejamento urbano mais sustentável.

No geral, o modelo criado para previsão das temperaturas durante o dia apresentou bom desempenho. Entretanto, para o período noturno é preciso repetir a metodologia com a adoção de novos parâmetros urbanísticos para o treinamento de novas redes neurais. Além disso, é importante também ampliar as faixas de dados de entrada nas redes neurais, para caracterização de diferentes ambientes urbanos e outros índices urbanísticos.

\section{Referências}

ABREU-HARBICH, L. V.; LABAKI, L. C.; MATZARAKIS, A. Influence of Different Urban Configurations on Human Thermal Conditions in a Typical Subtropical Coast City: case of Santos, São Paulo. In: INTERNATIONAL CONFERENCE ON URBAN CLIMATE JOINTLY, 9.; SYMPOSIUM ON THE URBAN ENVIRONMENT, 12., Toulouse, 2015.

Proceedings...Toulouse, 2015.

AMIRTHAM, L. R.; HORRISON, E.; RAJKUMAR, S. Impact of Urban Morphology on Microclimatic Conditions and Outdoor Thermal Comfort: a study in mixed residential neighbourhoodof Chennai, India. In:

INTERNATIONAL CONFERENCE ON URBAN CLIMATE JOINTLY, 9.; SYMPOSIUM ON THE URBAN ENVIRONMENT, 12., Toulouse, 2015. Proceedings...Touluse, 2015.

ANDREOU, E. Thermal Comfort in Outdoor Spaces and Urban Canyon Microclimate.

Renewable Energy, v. 55, p. 182-188, jul. 2013. 
BOURBIA, F.; BOUCHERIBA, F. Impact of Street Design on Urban Microclimate for semi Arid Climate (Constantine). Renewable Energy, v. 35, n. 2, p. 343-347, 2010.

CARFAN, A. C.; GALVANI, E.; N. J. T. Study of the Microclimate Effect in the Urban Vertical Structure in Ourinhos, São Paulo State.

ActaScientiarum, Maringá, v.34, n. 3, p.313-320, jul./set. 2012.

CHEN, L.; NG, E. Quantitative Urban Climate Mapping Based on a Geographical Database: a simulation approach using Hong Kong as a case study.International Journal of Applied Earth Observation and Geoinformation, v. 13, n. 4, p. 586-594, 2011.

COHEN, P.; POTCHTER, O.; MATZARAKIS, A. Human Thermal Perception of Coastal Mediterranean Outdoor Urban Environments. AppliedGeography, v. 37, p. 1-10, fev. 2013.

DEBIAZI, P. R.; SOUZA, L. C. L. Avaliação do Ambiente Térmico de Um Campus Universitário Com o Auxílio de Uma Plataforma SIG. In: ENCONTRO NACIONAL DE CONFORTO NO AMBIENTE CONSTRUÍDO, Campinas, 2015. Proceedings...Campinas, 2015.

DIMOUDI, A. et al. Investigation of Urban Microclimate Parameters in an Urban

Center.Energy and Buildings, v. 64, p. 1-9, 2013.

EL-SHAFIE, A.et al. Optimized Neural Network Prediction Model for Potential Evapotranspiration Utilizing Ensemble Procedure.Water Resources Management, v. 28, n. 4, p. 947-967, 2014.

GÓMEZ, N.; HIGUERAS, E.; ESCALONA, M. Técnica Estadística de Evaluación de Sostenibilidad del Microespacio entre Edificaciones en Clima Cálido Húmedo. In: CONGRESSO LUSO-BRASILEIRO PARA PLANEJAMENTO URBANO, REGIONAL, INTEGRADO E SUSTENTÁVEL, Lisboa, 2014. Anais... Lisboa, 2014.

HIEN, W. N.; JUSUF, S. K. Air Temperature Distribution and the Influence of Sky View Factor in a Green Singapore Estate.Journal of Urban Planning and Development, v. 136, n. 3, p. 261 272, 2010.

HOUET, T; PIGEON, G. Mapping Urban Climate Zones and Quantifying Climate Behaviors: an application on Toulouse urban area (France). Environmental Pollution, v. 159, n. 8, p. 21802192, 2011.
JOHANSSON, E. et al. Instruments and Methods in Outdoor Thermal Comfort Studies: the need for standardization. UrbanClimate, v. 10, n. 2, p. 346-366, dez. 2014.

LÓIS, É.;LABAKI, L. C.; SANTOS, R. F. Efeitos de Diferentes Estruturas de Vegetação Ciliar Sobre as Variáveis de Microclima e a Sensação de Conforto Térmico. Revista do Instituto Florestal, São Paulo, v. 23, n. 1, p. 117-136. jun. 2011.

MARROQUIM, F. M. G.; CRUZ, M. S.; BARBIRATO, G. M. A Influência do Desenho Urbano no Ambiente Térmico Resultante de Um Empreendimento do Programa Minha Casa Minha Vida em Clima Quente Úmido do Nordeste Brasileiro. In: CONGRESSO LUSOBRASILEIRO PARA PLANEJAMENTO URBANO, REGIONAL, INTEGRADO E SUSTENTÁVEL, Lisboa, 2014. Anais...Lisboa, 2014.

MATZARAKIS, A.; RUTZ, F.; MAYER, H. Modelling Radiation Fluxes in Simple and Complex Environments: basics of the RayMan model. International Journal of Biometeorology, v. 54, n. 2, p. 131-139, set. 2010.

OKE, T. R. City Size and the Urban Heat Island. Atmospheric Environment, v. 7, n. 8, p. 769-779, ago. 1973.

OPEN STREET MAPS. [Mapa]. Disponível em <https://www.openstreetmap.org> Acesso em: 23 out. 2015 .

PATEL, D. A.; JHA, K. N. Neural Network Approach for Safety Climate Prediction.Journalof Management in Engineering, v. 31, n. 6, p. 05014027, 2014.

ROCHA, L. M. V.; SOUZA, L. C. L. Contribuição da Vegetação e Permeabilidade do Solo Para o Ambiente Térmico em Avenidas de Fundo de Vale. In: ENCONTRO NACIONAL SOBRE CONFORTO NO AMBIENTE CONSTRUÍDO, Búzios, 2011. Anais... Búzios, 2011.

SHAHRESTANI, M.et al.A Field Study of Urban Microclimates in London. Renewable Energy, v. 73, p. 3-9, 2015.

SILVA, A. N. R. D. et al.SIG: uma plataforma para introdução de técnicas emergentes no planejamento urbano, regional e de transportes. São Carlos: Edição dos autores, 2004.

SOUZA, L. C. L. Relações Entre Ilhas de Calor, Geometria Urbana e Consumo de Energia Elétrica. Fórum Patrimônio: Ambiente Construído e Patrimônio Sustentável,Belo Horizonte, v. 4, n. 1, jan./jun. 2010. 
SOUZA, L. C. L. et al. Fator de Visão do Céu e Intensidade de Ilhas de Calor na Escala do Pedestre. Ambiente Construído, Porto Alegre, v. 10, n. 4, p. 155-167, out./dez. 2010.

STEINIGER, S.; HUNTER, A. J. S. The 2012 Free and Open Source GIS Software Map: a guide to facilitate research, development, and adoption.

Computers, Environment and Urban Systems, v. 39, p. 136-150, 2013.

STEWART, T. J.; JANSSEN, R. A

MultiobjectiveGIS-Based Land Use Planning Algorithm.Computers, environment and urban systems, v. 46, p. 25-34, 2014.

WANG, Y.; AKBARI, H. Effect of Sky View Factor on Outdoor Temperature and Comfort in Montreal. Environmental Engineering Science, v. 31, n. 6, p. 272-287, 2014.

WONG, P. P. et al. The Impact of Environmental and Human Factors on Urban Heat and Microclimate Variability.Building and Environment, v. 95, p 199-208, 2016.

XIAODONG, H. et al. Quantitative Detection of Urban Climate Resources and the Establishment of an Urban Climate Map (UCMap) System in Beijing.Building and Environment, v. 92, p. 668678 , out. 2015
YAN, H. et al. Assessing the Effects of Landscape Design Parameters on Intra-Urban Air

Temperature Variability: the case of Beijing, China. Building and Environment, v. 76, p. 4453, jun. 2014.

ZHANG, B. et al. The Cooling Effect of Urban Green Spaces as a Contribution to Energy-Saving and Emission-Reduction: a case study in Beijing, China.BuildingandEnvironment, v. 76, p. 37-43, jun. 2014.

\section{Agradecimentos}

Cordialmente agradecemos à equipe do Núcleo de Pesquisas Acústicas e Térmicas nas Edificações e Redes Viárias (Nupa) da Universidade Federal de São Carlos, em especial a pós-doutoranda Márcia Thais Suriano. Agradecemos também à prefeitura do Campus, por permitir a instalação dos equipamentos. Por fim, agradecemos à Coordenação de Aperfeiçoamento de Pessoal do Nível Superior (Capes) e ao Conselho Nacional de Desenvolvimento Científico e Tecnológico (CNPq), pelo apoio financeiro em diversas etapas dessa pesquisa.

Pedro Renan Debiazi

Faculdade de Arquitetura e Urbanismo | Estácio Carapicuíba | Av. Francisco Pignatari, 630, Vila Gustavo Correia | Carapicuíba - SP Brasil | CEP 06310-390 | Tel.: (17) 99791-3199 | E-mail: arq.pedrodebiazi@gmail.com

Léa Cristina Lucas de Souza

Centro de Ciências Exatas e de Tecnologia | Universidade Federal de São Carlos | Rodovia Washington Luis, km 235, Monjolinho | São Carlos - SP - Brasil | Caixa Postal 676 | CEP 13565-905 | Tel.: (16) 3351-9692 | E-mail: leacrist@ufscar.br

\section{Revista Ambiente Construído}

Associação Nacional de Tecnologia do Ambiente Construído

Av. Osvaldo Aranha, $99-3^{\circ}$ andar, Centro

Porto Alegre - RS - Brasil

CEP $90035-190$

Telefone: +55 (51) 3308-4084

Fax: +55 (51) 3308-4054

www.seer.ufrgs.br/ambienteconstruido

E-mail: ambienteconstruido@ufrgs.br 